\title{
Aesthetic Comparison between Chinese and Western Classical Gardens
}

\section{Chuandai Qiao}

School of Foreign Language, Hubei University of Automotive Technology, Hubei 442002, China.

alucy521@126.com

Keywords: Classical gardens; aesthetic comparison; artistic beauty.

\begin{abstract}
The establishment of Chinese garden aesthetics can be traced back to the era of the Wei (220-265 A.D.), Jin (265-420 A.D.) and the Southern and Northern dynasties (420-589 A.D.).The specific historical conditions forced the literati-official class to ignore politics, indulge themselves to natural landscape and express their feelings in the natural beauty of lakes and mountains, making Chinese gardening full of randomness and occasionally. If we make a general survey of the garden, we will find that the layout is always changing, and there is not strict subordinate relationship between the whole and the part; the structure is very loose without regulation to follow. In the west, the ancients believed that art originated from the coordination of quantities, so they can produce the beauty as long as they adjust the proportion of quantities well. It is important in the art that the structure must be as clear, definite and logical as mathematics. So they calculated the beauty with numbers, trying to find out the most beautiful form and proportion in an attempt to use mathematical formulas to show.
\end{abstract}

\section{Introduction}

Chinese garden, although from the perspective of form and style, belongs to the natural landscape garden, is definitely not to simply reproduce or imitate of nature, but to summarize based on deep understanding of natural beauty. Gardeners often integrated some artificial mountains, waters, gardens, etc with some natural scenes like flowers, birds, insects, fish, etc to create new artistic conception. This kind of creation is in accord with the nature and can more deeply display the nature and attach their emotion, philosophy and ambition to the nature. In the west, the ancients believed that art originated from the coordination of quantities, as long as they adjust the proportion of quantities well, they can produce the beauty. It is important in the art that the structure must be as clear, definite and logical as mathematics. So they calculated the beauty with numbers, trying to find out the most beautiful form and proportion in an attempt to use mathematical formulas to show.

\section{The Artistic Beauty of Chinese Classical Garden VS. The Formal Beauty of Western Garden}

\subsection{The artistic Beauty of Chinese Classical Garden.}

Artistic conception is the highest pursuit of Chinese art creation, and it is a long lasting theme in Chinese classical aesthetics. As a part of Chinese classical culture, the garden also takes artistic conception as the highest pursuit. Chinese garden pays attention to the implication of poems and artistic conception of paintings, embodying a kind of poetic illusion everywhere. The artistic conception in the garden can cause people to ponder, associate and connect the physical environment with their mood together, creating a state of the fusion of feelings with the natural setting scenes. In gardening, Chinese ancient people were very good at messaging implied meaning. When choosing flowers and trees they often personified them and compared them to kind of spirits with unique characters, such as the vigorous pine, natural and unrestrained bamboo, delicate and charming malus spectabilis, varied willow, lofty winter sweet, distinguished peony, the colorful and splendid peony, honorable lotus (which lives in the silt but not imbrued"), and elegant orchid, etc. They were adept in making use of the shape of plants and the change of four seasons to convey certain feelings or to describe a certain artistic conception. For example, the saying "Only in the coldest season, we can see 
the tall and straight pines and cypress" is used for strong and faithful spirit; "Remain the withered lotus to listen to the rain", "looking through window at night, hearing the sound of rain dropping on the plantain" is to show a peaceful atmosphere; malus spectabilis (belonging to rose division) symbolizes the harmonious relations among brothers; pomegranate flower, "a single red flower in the midst of thick foliage" , is a metaphor meaning one being worth ten. The selection of trees also has its law. Planting pine in garden means "adding eyes to a dragon”; China fir is planted around the house, showing a spirit of perseverance; Chinese parasol pleases people's eyes and mind with dark green bark and round leaves like flowers.

\subsection{Beauty of Form in Western Garden.}

Since the day when Western aesthetics formed, it had been influenced by idealism aesthetics. Both Plato (427-347 B.C.) and Hegel (1770-1831) believed that the beauty of natural things rooted in the idea or God. Coleman thought that natural beauty comes from the heart of human. In a way, they all ignored and denied the natural beauty. French landscape gardener G. Gromort claimed that "Garden is an artificial composition. Our goal is not to try to simulate the chance of natural scenery. For us, what matters is to make the natural stylized.” The idealism aesthetics view on garden exaggeratedly attributed all the natural beauty to the beauty of the phenomenon, making the Western garden expand and extend only within the field of construction and obey the architectural composition rules. Therefore, the great philosopher Hegel came to the conclusion that the garden is not a complete art. Westerners believe that to reach a perfect situation in gardening, gardeners must improve the natural beauty by means of certain idea, so as to achieve the artistic beauty, namely a kind of formal beauty. Under such influence, Western gardeners deliberately pursue the beauty of geometric pattern. In their opinion, the garden must present a geometric relationship (such as symmetry of axis lines, balance) and geometrical shape (such as linear, square, round triangle, etc). Although the combination can be varied and changeable, there are still rules to follow. Since Western garden deliberately pursues the formal beauty, it can not violate the principle of form beauty. Therefore, all the elements of the garden can not be divorced from the overall, and must be embedded in a certain position in certain shape and size, showing a kind of inevitability conforming to the law.

\section{The Natural Beauty of Chinese Garden VS the Artificial Beauty of Western Garden}

The Chinese garden devotes particular care to the reproduction of nature. "Out of nature, higher than nature" is a typical character of Chinese classical garden. Take the "piling rockeries" and "artificial waterscape" for example, the "piling rockeries" is to build the peak, hill, ridge, valley, cliff and steep, etc on a smaller scope by simulating the overall perspective of a physical mountain or capturing part of the mountain. From the stacked structure and composition, we can see it is a generalization and refinement of the law of natural mountains. The artificial hills in the garden are abstraction and typification of the physical mountain; all of the waters are also the abstract generalization of the river, lake, sea, pond, stream, creeks, spring and waterfall, etc in nature. According to the physical terrain and specific circumstance of the garden, big or small, straight or curved, moving or moveless, gardeners make use of the various waters to decorate the rockery shore or connect islands and build bridge to create an artistic conception of meandering shores and water tunnel, seeming divided but being connected. They tried to simulate the complete picture of natural waters in a limited space as possible as they could, demonstrating the conception of "a scoop of clear water can show the magnificent rivers and lakes". The idea of advocating nature in the Chinese garden firstly shows the special aesthetic tastes of Chinese people. The gentle and natural aesthetic principle, although, is based on the scale of human nature on the one hand, is closely related to the idea of advocating nature. For example, the essence of gardening is to "borrow scenes". People often say that there are wonderful scenes outside the garden, so the great part lies in borrowing scenes outside to set off the inside; there are more beautiful scenes beyond because of the changing seasons. So flowers, trees, the sound of wind, birds..., all the visible or invisible scenes are interwoven together to compose a beautiful song. This is the best part of Chinese classical gardens. Manmade as they are, all the mountains, waters and gardens are just integrated with the flowers, birds, insects and 
fish, odd and charming mountains and waters in nature to compose a seamless natural landscape. Although, on respective of the form and style, Chinese garden belongs to the natural landscape garden, it is definitely not a simple reproduction or imitation of nature, but an extraction, abstraction, generalization and typification on the basis of deeply understanding of the natural beauty. This kind of creation is not contrary to the nature; instead, it conforms to the nature and reflects it more profoundly. Chinese garden stresses the natural beauty very much and takes it as the basis for judging the level of garden. The gardeners will always prefer to receive such evaluation like "to imitate nature as nature", and what they are most worried about is that people talk about the artificializaion and craftsmanship of the garden.

The natural beauty was also mentioned in Western aesthetic works, but they believe that the natural beauty itself was flawed which would not attain to perfection without being transformed by people. That is to say, the natural beauty itself did not have the aesthetic significance. Any things in the nature are free on birth and must inevitably be defective, so they can't be sublimate to become artistic beauty. The garden is artificially built, so it should be transformed in accordance with people's will to attain to perfection. From the perspective of phenomenology, the western gardening was mainly based on the use of artificial method to change the natural condition. The materials in western gardening from masonry to plant were mostly processed into an ideal shape through manpower, which highlights the transformation of human to the nature. The basic layout mainly employed regular array and geometric shape. In addition, the survival pattern of much land and few people made the western garden on the whole take on a broad horizon and magnificent momentum under the controlling of the axial symmetry. Western style garden focuses on the formal beauty of external geometric order. At the same time, it pays more attention to the function of garden, namely people-oriented. So very early there were outdoor recreation places with specific functions such as theaters, galleries, maze gardens, and swimming pools, etc, fully embodying the world outlook that all human activities are serving for people.

\section{Summary}

Chinese garden gives priority to being implicit, illusory, reserved and prefers implication, taking people inside a bewildering situation and generating endless illusion. This is of course because of the Chinese people's aesthetic habits and concept. If we say they pay attention to landscape, they will explore the materials and inspiration from the nature; the more the thing is in line with the nature, the more it contains rich connotation. Different from westerners, Chinese people know about thing more by means of direct recognition of it (directly experience it). They believed that that intuition is not a direct reaction to the sense, but a kind of mental activity, a sublimation inner experience, which can not be obtained through the method of reasoning. Chinese gardening usually borrows poems and paintings to strive for implicitness, deepness and illusion, whereby it can achieve the effect of seeing small in large, seeing large in small, mixing of reality and fantasy, hiding or appearing, etc, which makes many factors completely opposing to each integrated together and become a unified entity whereas without clear to speak of. On the contrary, it always makes people feel hazy, vague. With clear subordination, Western gardens make the focal points stand out and each part clear and definite; the boundary and space scale are clear at a glance; the space sequence is arranged clearly giveing people the impress of orderliness and clearness. Following the principle of formal beauty shows a kind of regularity and necessity, and whatever things with regularity will give people a sense of clear order. In addition, westerners are good at logical thinking, and they are accustomed to using analytical methods to reveal the essence. This kind of social ideology has greatly affected people's aesthetic habits and ideas.

\section{References}

[1] Liu Dunzhen and Joseph C. Wang. Chinese Classical Gardens of Suzhou. McGraw-Hill 12-13 (1993) 
[2] Mac Cannell D. Staged authenticity: Arrangements of Social Space in Tourist Settings. American Journal of Sociology, 14-16(1973)

[3] Herbert D. Literary Places, Tourism and the Heritage Experience. Annals of Tourism Research, 25-26(2001).

[4] Bruner, EM. Tourism, Creativity, and Authenticity. Studies in Symbolic Interaction, 9-11(1989) 